\title{
THE ORIGIN OF MAN
}

\author{
BY DR. R. BRoom, F.R.S, \\ Transvaal Museum, Pretoria
}

$\mathrm{W}$ HEN, in 1924, Dart of Johannesburg discovered a type of fossil anthropoid more manlike than the chimpanzee or gorilla, a new chapter was opened in the early history of man. Dart named his fossil form Australopithecus africanus, and he regarded it as somewhat intermediate between the living anthropoids and man, and probably near to the anthropoid from which man arose. The first account of the discovery was given in NATURE of February 7, 1925 .

The skull which Dart had discovered was unfortunately that of a young child-ape of about five years, and a few of the rather striking human resemblances were no doubt due to the immaturity of the specimen; and the majority of men of science were not inclined to accept Dart's opinion. They regarded the animal as closely allied to the chimpanzee, though with a few human characteristics apparently acquired by a parallel development. One authority considered that the skull is only "the distorted skull of a chimpanzee".

A few of us have consistently maintained since 1925 that Australopithecus is not only not a chimpanzee, but also that it is not at all closely allied to the chimpanzee, and that it has many characters that prove it to be near to the human ancestor.

In 1929 Dart removed the lower jaw from the upper and revealed for the first time the occlusal surfaces of the crowns of the milk molars. The side view of these teeth had shown that they were markedly different from those of the chimpanzee and gorilla, and were very like those of man. The

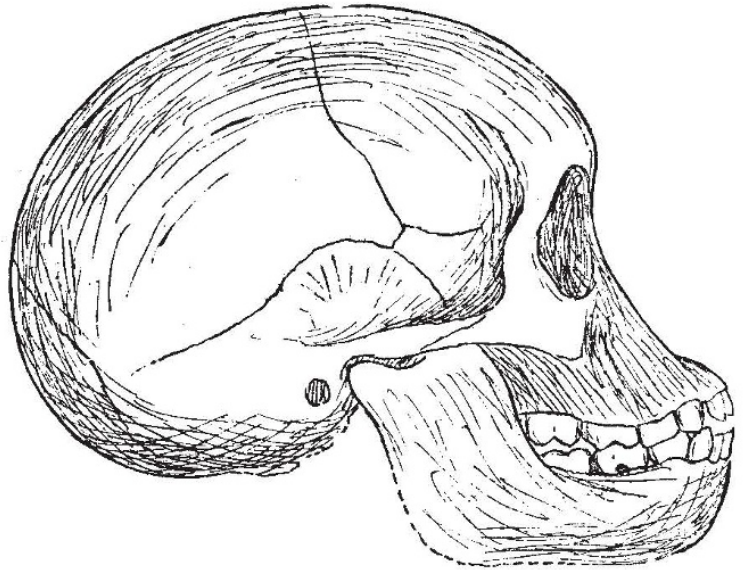

Fig. I.

SIDE VIEW OF SKULL of Australopithecus africanus DART. $\frac{1}{2}$ NATURAL SIZE.

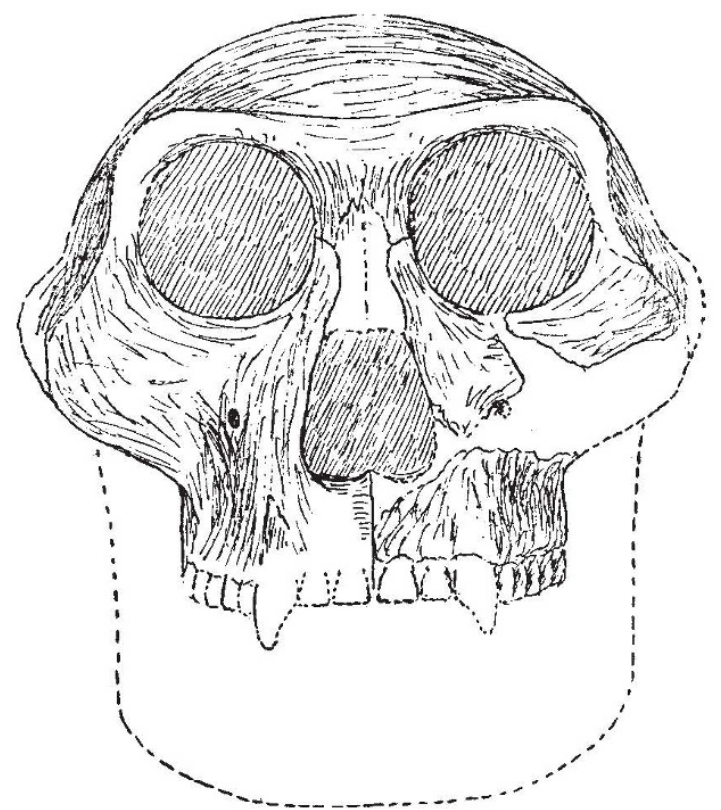

Fig. 2.

Front view of FACE OF Plesianthropus transvaalensis (BROOM). $\frac{1}{2}$ NATURAL SIZE. THE PARTS SHADED ARE KNOWN IN THE TYPE. THE MANDIBLE IS UNKNOWN IN THE TYPE, BUT CONSIDERABLE PORTIONS ARE KNOWN IN OTHER SPECIMENS.

occlusal surfaces now fully confirmed this view. They showed that Australopithecus cannot be nearly allied to any of the living anthropoids.

The first upper milk molars in the gorilla and chimpanzee have two main cusps. In man there are three ; and Australopithecus agrees with man. The first lower milk molar in the gorilla is a flattened tooth with one large pointed median cusp and indications of small anterior and posterior cusps. In fact, it is not unlike the premolars of the dog. In man the first lower milk molar is entirely different. It is a molariform tooth with four well-marked cusps. In Australopithecus the tooth agrees closely with that of man. In the chimpanzee the tooth is like that of the gorilla with some rudiments of the ancestral condition. By no possibility can man have been derived from an anthropoid with degenerate and specialized teeth like those of the gorilla or chimpanzee. The four cusps which we find in man and Australopithecus are manifestly the four cusps found in the milk molars of the cercopithecids, such as the baboon. Man must have come from an anthropoid which still retained the cercopithecid type of 
milk molars; and must have had a remote cercopithecid ancestor.

We need not here discuss the brain of Australopithecus. Dart and Elliot Smith considered that it showed some strikingly human characters; others thought the case not proved. Dart even went so far as to maintain that the structure of the brain showed that it was a bipedal animal, like man.

As Dart's type was only the skull of a young child-ape, the world remained unconvinced, and wanted an adult skull. So in $1936 \mathrm{I}$ set about looking for one, and in a few weeks was successfuJ ; and not only got one, but parts of three others with many isolated teeth. Then in 1938 I got a good skull of what I consider to be a third new genus of man-like ape.

For many months I have been working at the Sterkfontein type skull, and have now completed a reconstruction of it; and it seems but right to reveal at the earliest possible moment how this anthropoid looked. I shall not here discuss at length my reasons for regarding this Sterkfontein ape as belonging to a distinct genus from Australopithecus. Manifestly the two forms belong to very different geological ages. The Sterkfontein, which I call the Plesianthropus transvaalensis, is probably of Middle Pleistocene age. The Taungs ape is almost certainly very much older. Probably it belongs to the Lower Pleistocene, but just possibly it may be Upper Pliocene.

Plesianthropus, as will be seen from the illustrations, has a skull somewhat like that of the chimpanzee in size, but differing greatly in many char-
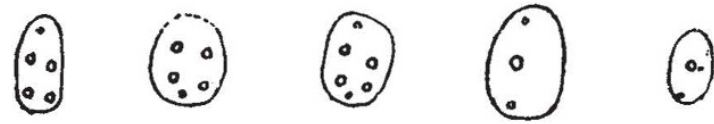

a

b

$c$

$d$

Fig. 3 .

DIAGRAMS OF THE CUSPS IN THE FIRST LEFT LOWER MILK MOLARS IN various Primates. $a$, BABOON; $b$, Australopithecus ; $c$, Bushman ChILD; $d$, GORILA; $e$, CHIMPANZEE (ALL NATURAL SIZE).
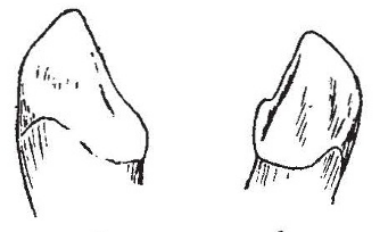

$a$

Fig. 4.

INNER SIDES OF LOWER CANINES OF ANTHROPOIDS (NATURAT SIZE). $a$, CANINE From YUNNAN, REGARDED BY WEIDENREICH AS CANINE OF AN ORANG, BUT BY THE WRITER AS MORE PROBABLY AUSTRALOPITHECINE CANINE AND POSSIBLY THE CANINE OF Gigantopithecus (FROM CAST); $b$, CANINE OF MALE Plesianthropus transvaalensis.
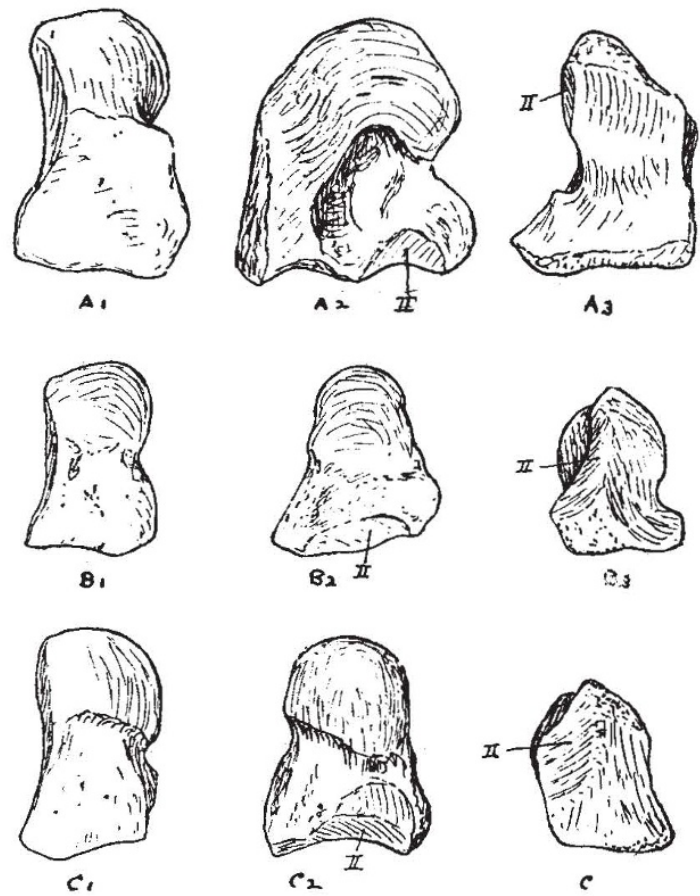

Fig. 5 .

The OS CAPITATUM (OR OS MAGNuM) OF THE CHIMPANZEE $A 1, A 2$ AND $A 3$; OF THE STEREFONTEIN APE $B 1, B 2$ AND $B 3$; AND OF THE BUSHMAN $C 1, C 2$ AND C3. Dorsat, Radial aND DIstar gIDEs. The ARTICULAR SURFACES INDICATED BY II ARE THOSE FOR THE IIND METACARPAIS.

acters. Though the skull is that of a male, the canine, though fairly large, is unlike that of the chimpanzee, and there is practically no diastema between it and the second incisor. The cheeks are broad and more like those of the gorilla and orang than those of the chimpanzee. The nasal bones are only partly known, but from the upper parts of the maxillæ we can be confident that the nose must have been more man-like than ape-like.

The teeth, though a little larger than those of man, are almost typically human, and not very like those of either the chimpanzee or gorilla (Figs. 3 and 4).

The most interesting tooth in Plesianthropus is the lower canine. It is of a type almost unique. It differs markedly from the lower canines of the living anthropoids, and there are no known fossil canines at all like it, except one. On the posterior border of the tooth there is a very distinct small cusp with, in front of it on the outer side, a moderately deep vertical groove, and on the inner side in front of it a very deep groove. This little cusp is a typical cercopithecid character lost in all known anthropoids, except one. Weidenreich figures a lower canine from a cave at Yunnan which he refers to a "fossil orang". In my opinion this is unlikely to be the canine of an orang.

Von Königswald has described some teeth of a 
large anthropoid under the name Gigantopithecus blacki. These were found in Chinese drug stores, and are believed to have come from somewhere in southern China (possibly Yunnan). One of these teeth, a second upper molar, so closely resembles the molars of the Kromdraai skull, Paranthropus, though very much larger, as to suggest that Gigantopithecus will prove to be an Australopithecine. Possibly Weidenreich's supposed fossil orang tooth came from the same locality, and will prove to be the lower canine of Gigantopithecus. In any event it is a tooth essentially similar in structure to the lower canine of Plesianthropus, and thus most probably an Australopithecine canine. Occasionally in man we find distinct evidence of this cercopithecid cusp, but usually it is lost in man as in the living anthropoids.

As I have recently shown, Plesianthropus has a maxillary antrum, which is fairly similar to that of man, and not at all like that of the chimpanzee.

The lower end of a femur which we may regard as practically certainly that of Plesianthropus closely resembles the femur of the Bushman, and is not like that of any of the living anthropoids. The only known wrist bone is very similar to that of a Bushwoman and differs greatly from that of the chimpanzee. I recently gave a figure of this os magnum or os capitatum, and for comparison the corresponding bones in some other Primates. Unfortunately, the supposed chimpanzee bone figured is really that of the orang. I theréfore give a few other figures to avoid any possible confusion. Curiously enough the chimpanzee bone is less like that of Plesianthropus than is that of the orang,

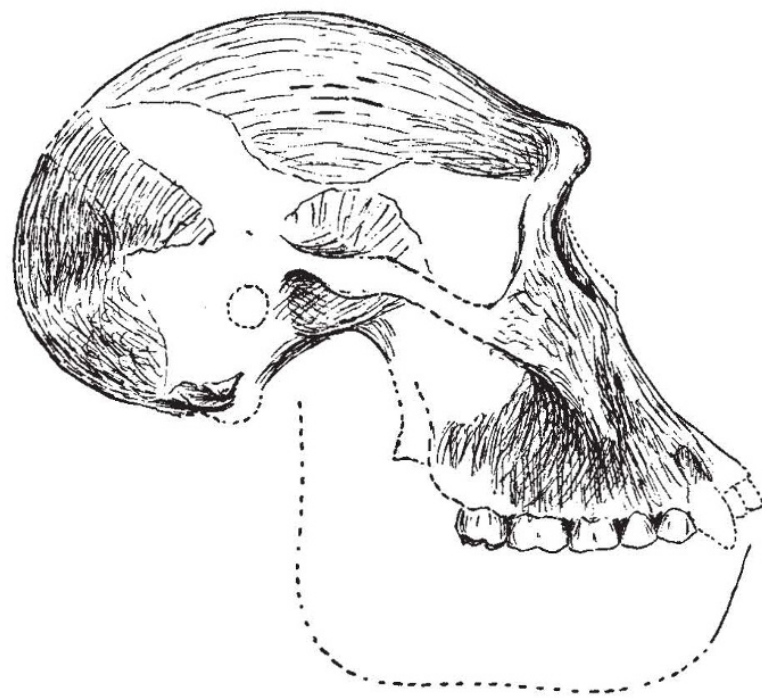

Fig. 6.

SIDE VIEW OF SKULL of Plesianthropus transvaalensis (Broom). Approx. $3 / 7$ Nat. Size. The parts SHADED ARE ALL KNOWN IN THE TYPE SPECIMEN. TWO OF THE TEETH ARE DRAWN FROM THOSE OF THE LEFT SIDE. THE SKULL IS THAT OF A MALE.

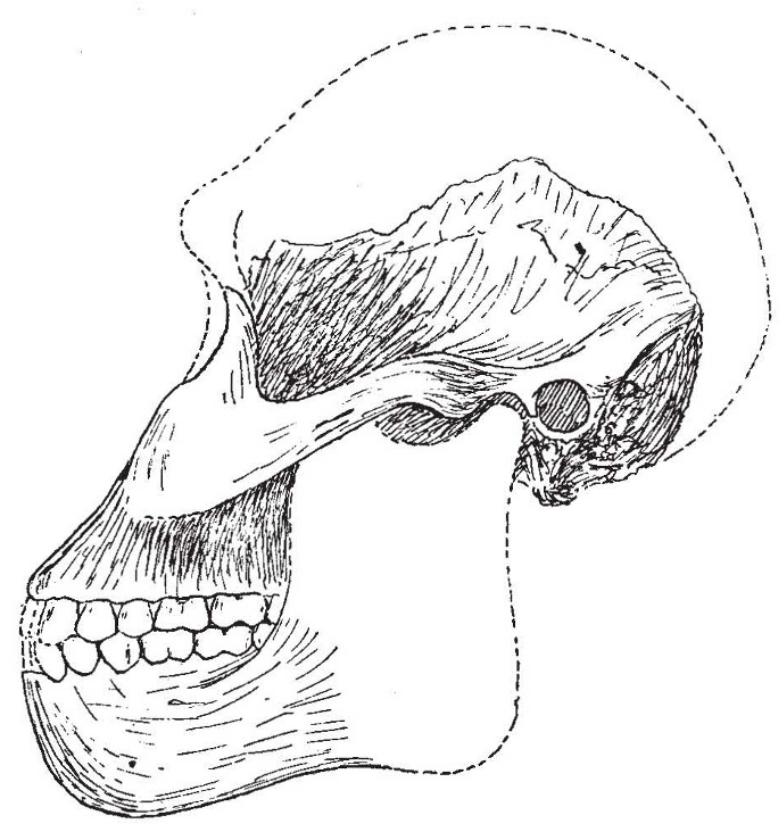

Fig. 7.

Side view of the Kromdraal skull, Paranthropus robustus (BROOM). APPROX. $3 / 7$ NATURAL SIZE.

THE SKULL IS PROBABly that of a Male.

and it is distinctly more baboon-like, though it has no os centrale (see Fig. 5).

In neither the orang, the gorilla nor the chimpanzee is the os capitatum like that in man. One very important difference is that in man the distal end of the bone gives a large articulation to the second metacarpal. In the chimpanzee and gorilla the distal end gives no articulation to the second metacarpal in the specimens I have examined, but there is a small articulation for it on the radial side. In the orang there is a similar radial articulation and a small distal articulation. In Plesianthropus the condition is essentially as in man, with a large articulation on the distal end for the second metacarpal. Probably the large articulation for the second metacarpal in man is due to the greater development of the metacarpal in connexion with the well-developed thumb. In the orang the thumb is better developed than in the gorilla and chimpanzee, and here there is a small distal articulation on the os capitatum for the second metacarpal. We are perhaps justified in concluding from the structure of the os capitatum in Plesianthropus that it, like man, had a useful opposable thumb.

The Kromdraai ape, Paranthropus robustus, is a third type of South African Australopithecid. It differs in many characters from Plesianthropus. It has a smaller canine and a very differently shaped face, and the premolars are much larger and differently shaped. It is also of a different geological age. The baboons associated with it 
are of different species from those at Sterkfontein, and so are the species of Procavia. Though probably of Middle Pleistocene age, it may be many thousands of years older than Plesianthropus.

The skull gives us the perfect glenoid cavity which is almost typically human in structure, and quite unlike that of either the chimpanzee or the gorilla. The brain is probably considerably larger than that of Plesianthropus. Though only some fragments of the mandible of Plesianthropus are known, we have a good lower jaw of Paranthropus. Its teeth are almost typically human, but the premolars are very large; while the canines are remarkably small.

We have the distal end of the humerus and the proximal end of the ulna of Paranthropus. These were found with the type skull, and there cannot be the slightest doubt that they belong to the same individual. They are almost typically human in structure, and very unlike those of the living anthropoids.

The South African caves have shown us that there lived in Pleistocene times various anthropoids which in many characters were much nearer to man than the living anthropoids. They had larger brains, and almost the human type of teeth, and there is considerable reason to believe they were mainly bipedal. They certainly were not arboreal, and they probably hunted in packs. There is reason to believe that they used sticks or stones for digging and as weapons. We can scarcely doubt that, though not yet human, they were nearly related to man.

Man was undoubtedly on the earth in Upper Pliocene times and must thus have been living in Europe and Asia when the known Australopithecines were inhabiting South Africa. Though it is thus improbable that any of the known South African Australopithecines can have been the ancestors of man, the discovery of these very manlike anthropoids shows us that there once lived a group of anthropoids so near to man in structure that we seem forced to believe that man has come from a Pliocene Australopithecine.

Though the gorilla is well removed from man's ancestor, he must be more nearly related to man than is the chimpanzee. Man and Australopithecus have retained a number of cercopithecid characters lost in the living anthropoids, but manifestly the gorilla and chimpanzee must have had cercopithecid ancestors. The cercopithecids have very marked ischial callosities. These are retained in the gibbons, and are occasionally well marked in the chimpanzee, but are lost in the orang, the gorilla and man.

Some years ago I argued that man must have sprung from a heavily built anthropoid such as the gorilla, which had to use its hallux for support, otherwise he would have lost his great toe, as has the kangaroo to-day. If I am right in assuming that Gigantopithecus was probably an Australopithecid we have perhaps in this giant form an anthropoid very near to that from which man arose.

The structure of the teeth in man and the Australopithecines seems to prove conclusively that man and the anthropoids must have come through a cercopithecid line as they have cercopithecid characters not found in the lemurs or the tarsioids. The living anthropoids have lost

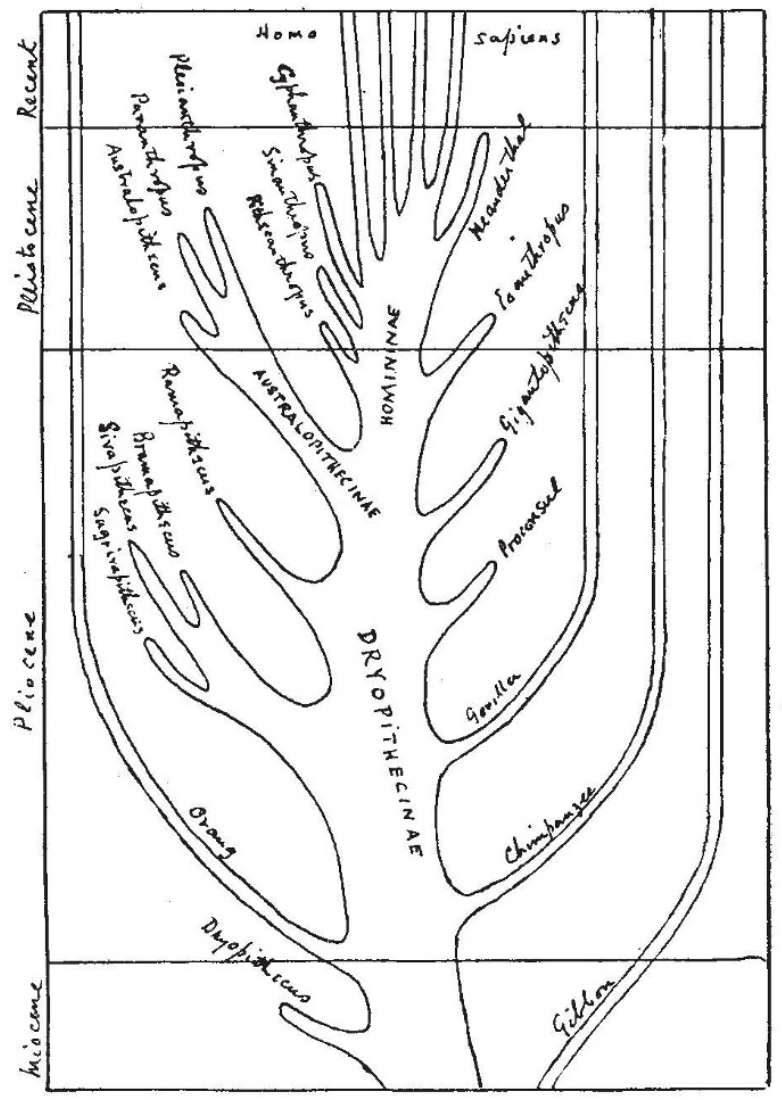

Fig. 8.

Phylogenetic Relationships of MAN AND THE HIGHER ANTHROPOIDS.

many of the cercopithecid tooth characters, but the orang retains sufficient to leave no doubt of the cercopithecid ancestry.

I think there can be no reasonable doubt that man arose in Middle or more probably Upper Pliocene times from a large Australopithecine ape. The known Australopithecines are near relatives of this ancestor. The living anthropoids are much more remote relatives.

Though there are many who object to genealogical trees-and certainly some of those that have been published have been unsatisfactory-someone must be correct ; and the one I here give may 
with further knowledge have to be modified, but $I$ think it cannot be very far from the truth.

In the tree I give, attention may be directed to the placing of Ramapithecus nearer to the base of the human stem than the other Siwalik types, and to the placing of Proconsul higher up than is usually done. Hopwood regards Proconsul as a Lower Miocene form "related to Dryopithecus and ancestral to the chimpanzee". I have only seen the cast, but incline to place it nearer to the gorilla, and appreciably higher. Possibly the supposed Miocene age is wrong.

The reasons for the various conclusions to which I have come will be given at length in the long paper I have in hand on the South African Pleistocene Anthropoids.

\section{A NEW PROCESS FOR LIQUEFYING AIR}

\section{By J. H. AwBERY}

$\mathrm{I}^{\mathrm{N}}$

$N$ nearly all refrigeration processes, whether for the moderate cooling associated with focd preservation or for the liquefaction of the 'permanent' gases, the operations are basically similar. A gas or vapour is compressed, the heat due to this compression is removed, and the fluid then allowed to expand, whereby it cools below the temperature of its surroundings. In the Linde process for making liquid air, the compression is to about 200 atmospheres, and the expansion takes place through a nozzle, the resulting cooling being that due to the Joule-Thomson effect; the process is made cumulative by using the cold air to lower the temperature of the air which is still approaching the nozzle. Now the Joule-Thomson effect is by no means large in gases so nearly perfect as air, and it has long been realized that much greater cooling could be obtained in the expansion if this could be carried out in such a way that the gas did work, so that more energy would be removed from it. Mechanical difficulties, such as that of lubrication and of avoiding excessive heating due to friction, have caused designers to favour the theoretically less efficient expansion valve, though Claude had successfully applied the principle as early as 1906 .

In an article in Voks Bulletin (NovemberDecember, 1940), Prof. P. Kapitza gives a brief description of an installation which has now been set up at the Institute of Physical Problems of the Academy of Sciences of the U.S.S.R., in which the expanding air does work by driving a turbine. The increased temperature-fall, as compared with free expansion through a nozzle, is so great that the initial compression need only be of the order of 5 atmospheres, instead of the 200 atmospheres necessary in Linde's process.

The main difficulty to be overcome was the design of the turbine itself, which is quite inefficient if the axial-flow impulse turbine used with steam is taken as a model. Owing to the low temperature, the air flowing through the turbine has a density five times that of steam at $250^{\circ} \mathrm{C}$., so that there is a considerable centrifugal force as the fluid whirls around, and this must be taken into account, just as it is in a water turbine.

The present apparatus, which will be followed by larger ones, has a piston compressor working at 400 r.p.m., taking $50-80 \mathrm{kw}$. of electrical energy and delivering nearly $600 \mathrm{kgm}$. of air per hour at about 7 atmospheres. The compressed air then passes a. water cooler and through the regenerator (cooled by previously treated air) to the turbine. The latter works at 40,000 r.p.m. and yields $4 \mathrm{kwh}$. of mechanical energy. The pressure drop is 4 to 1 , and the cooling is such that air entering at $-158^{\circ} \mathrm{C}$. emerges at $-187^{\circ} \mathrm{C}$. (the boiling point of oxygen), implying the extraction of 3,700 calories per hour. The efficiency is thus $0 \cdot 79-0 \cdot 83$. The regenerators also offer some novel features. There are two of them, used intermittently for about 26 sec. each, the changeover being effected automatically. They are filled with flat ribbon, $0.1 \mathrm{~mm}$. thick and $50 \mathrm{~mm}$. wide, with nodules.

From the turbine, the main air-stream is passed through the inner tubes of a condenser, only a small by-passed stream flowing through the outer tubes and being liquefied therein. The overall efficiency of the apparatus is such that it gives 29-30 kgm. of liquid air per hour, at an energy cost of $1.7 \mathrm{kwh}$. per $\mathrm{kgm}$. It is calculated that this can be reduced to $1.2 \mathrm{kwh}$. per $\mathrm{kgm}$. by making use of the mechanical energy from the turbine and by more suitable valves and other equipment, so as to utilize the full seven atmospheres compression, instead of only four-sevenths of it. If so, the apparatus will have about the same efficiency as present high-pressure installations.

It is even hoped that by working on a much larger scale, where heat losses are relatively smaller, the efficiency may rise to $1 \cdot l$ or even $1.0 \mathrm{kwh}$. per $\mathrm{kgm}$. of liquid air. In any event, as a laboratory installation, the outfit has many advantages, noteworthy among them being the short starting period (20 minutes or less) and the small dimensions, due to absence of decarbonizers, scrubbers, desiccators and other auxiliary gear. 